
\title{
R Research Soutere \\ A Survey of Globodera Rostochiensis on Potato Crops in Himachal Pradesh; Occurrence and Detection.
}

\author{
Ashvika Pathania \\ Lovely Professional University https://orcid.org/0000-0002-3920-0312 \\ Joydeep Dutta ( $\square$ joydeep.dutta@lpu.co.in ) \\ Lovely Professional University \\ Shashank Garg \\ Lovely Professional University
}

\section{Research Article}

Keywords: Globodera, survey, soil sampling, plant parasitic nematode, potato crops, cyst nematode, percentage of occurence.

Posted Date: September 13th, 2021

DOl: https://doi.org/10.21203/rs.3.rs-770909/v1

License: (우 (i) This work is licensed under a Creative Commons Attribution 4.0 International License. Read Full License 


\section{Abstract}

A survey was carried out to estimate the frequency and occurrence of potato cyst nematode (PCN) in potato cultivating fields in different districts of Himachal Pradesh. A total of 109 composite soil samples were collected from 5 districts of Himachal Pradesh, India. Nematode cysts were extracted from the soil using standard procedure. The population density and percentage of occurrence of cyst nematode were calculated. According to the results district, Mandi had the highest PCN cyst population density, and the percentage of occurrence is $100 \%$. District Kangra had the least PCN cyst population density and the percentage of occurrence is $66.6 \%$. This survey showed the occurrence Globodera rostochiensis district-wise. The collected cysts were identified by morphological and molecular techniques, up to species level based on nucleotide homology and phylogenetic analysis. According to morphometrics distance between the vulva and anus is very less $(65.69 \pm 22.2) \mu \mathrm{m}$. The outcome sequences are showed $95-99.05 \%$ similarity with sequence I.D KJ636272.1 from the Netherlands. This survey indicates that PCN Globodera rostochiensis were widely distributed in the potato cultivating fields of Himachal Pradesh. The present study helped determine the distribution of PCN in the soil and species dominance in particular areas. Hence, it helps design different strategies against PCN management.

\section{Introduction}

Potato cyst nematode (PCN) is highly adaptive and cause damage to potato plants. It consists of two highly specialized species G. rostochiensis and G. pallida. Both show successful and long association with their host plants. PCN has a special ability to survive during adverse conditions and has high reproductive potential. Their resistant behavior for their survival makes it difficult to eradicate from the soil once established. Studies reported the presence of Globodera spp. in several countries (Table 1) and cause damage to tuber crops (Okhi et al. 2018). Variation in virulence of Globodera is also found in Europe and South American population on different species of potato (Phillips and Trudgill, 1998). PCN follows the unique life cycle, a dead female hardened their body, convert in the form of a spheroid or rounded shape cyst and protect the eggs within. After hatching infective juveniles can disperse up to $1 \mathrm{~m}$ in the soil. PCN infects plants by entering into the roots of the plants through the growing root tip, form feeding sites in the roots by modifying the root cells, nematode becomes sedentary. This infection leads to reduced root growth, a stunted shoot system, and poor productivity with ultimately leads to plant death (Mimee et al. 2015; Cotton et al. 2014). In the presence of the host plant, hatching can occur annually on an average $60-80 \%$ but about $20-30 \%$ of hatching can also take place in the absence of the host. The cyst can survive in the soil for the long period. PCN completed its life cycle 56-63 days both in the autumn and spring season (Ebrahimi et al.2014). Sexual reproduction occurs in nematodes. Sex attractant pheromones are secreted by the females to attract males for mating, nematodes mate several times in their life span. Each female produces 200-500 eggs, after the death cuticle of the dead female convert into the cyst. Under unfavorable conditions, eggs remain in the dormant stage inside the cyst. After receiving a hatching stimulus in the form of chemicals released from the host root, hatching occurs. Juveniles released from the cyst. PCN eggs can remain inside the cyst in the dormant stage up to 30 years and are resistant to many nematicides. Globodera spp. hatching generally occurs at $10 \mathrm{oC}$ or above. G. rostochiensis eggs hatch between $5-29{ }^{0} \mathrm{C}$ temperature In favorable temperature conditions second-stage juveniles hatch from the cyst and escape from the cyst moves towards 
the roots of the host plant (Kaczmarek et al. 2014). PCN can cause 33-54\% potato tuber yield loss which may be considered a serious threat to potato cultivation. With the increase in the rate of infestation by PCN, it's urgent to formulate strategies for its management as well as it's very important to check further spread in the potato field (Seenivasan 2017).

This study was conducted to evaluate the population density and frequency of occurrence of potato cyst nematode (PCN) G. rostochiensis on potato crops in Himachal Pradesh.

\begin{tabular}{|c|c|c|}
\hline Species & Country & Reference \\
\hline G pallida & Japan & Okhi et al. 2018 \\
\hline G pallida & Peru & Ponce, 1977 \\
\hline G pallida & Spain & Ponce, 1977 \\
\hline G. pallida & India & Ganguly et al. 2010 \\
\hline G. pallida & United Kingdom & Kaczmarek et al. 2014 \\
\hline G. pallida & India & Seenivasan 2017 \\
\hline G. pallida & Panama & Ponce, 1977 \\
\hline G. pallida & USA & Skantar et al. 2011 \\
\hline G. rostochiensis & Russia & Subbotin et al. 2000 \\
\hline G. rostochiensis & India & Seenivasan 2017 \\
\hline G. rostochiensis & India & Ganguly et al. 2010 \\
\hline G. rostochiensis & USA & Skantar et al. 2011 \\
\hline G. rostochiensis & Bolivia & Ponce, 1977 \\
\hline G. rostochiensis & United Kingdom & Kaczmarek et al. 2014 \\
\hline G. rostochiensis & Guatemala & Ponce, 1977 \\
\hline G. sandveldensis & South Africa & Knoetze et al. 2017 \\
\hline G tabacum & Italy & Subbotin et al. 2011. \\
\hline G. tabacum & USA & Skantar et al. 2011 \\
\hline G. mexicana & Mexico & Subbotin et al. 2011. \\
\hline
\end{tabular}

\section{Material And Methods}

Survey and soil sampling: Random survey was conducted in different districts of Himachal Pradesh during 2018-2021 where potato is cultivated in all three seasons i.e spring-summer and autumn year after year at 
elevation $465 \mathrm{~m}-7000 \mathrm{~m}$ (1526ft-23000ft). For soil sampling two available methods were followed to collect samples from the fields:

1) By collecting soil samples around the plant rhizosphere and processing them into the laboratory. 2) By lifting plants gently and examining roots either in the field or in the laboratory for cyst/females. These methods have been used to detect the population of cysts in the soil. Cyst nematode host plants are available during a part of the year but highly resistant cysts remain available in the soil throughout the year. A soil sample should be taken randomly and in large amounts to achieve accuracy. A soil sample must be taken repeatedly from the same field to ensure the presence of a cyst. To achieve $90 \%$ of probability of detection of cyst nematode total sample size must be $6.9 \mathrm{KG} / 0.33$ hector best for comprising a minimum sample with the maximum probability of detecting cyst. The only aim of sampling is to achieve a high level of probability for getting cyst nematodes with a high level of accuracy (Wainer and Dinh 2021). A total of 109 soil samples were collected from 7distt. The soil sample was collected from the root rhizosphere of the potato plant. The cysts were extracted from the soil by using 100 mesh sieve and 60 mesh sieve from $250 \mathrm{ml}$ of a soil sample by Fenwick method (Fenwick 1940). The cyst was hand-picked with the help of a sterilized brush and forceps under a stereo zoom microscope. The collected cyst was subjected to morphological and molecular characterization for identification up to species level.

Population density (P.D) and percentage of occurrence were calculated (Bakr et al. 2011)

P.D. $=$ No. of nematodes $/$ total no. of samples. $\%$ occurrence $=$ No. of positive samples $/$ total no. of samples $\times 100$

Morphological identification: pure population of the collected cyst was subjected for morphological and morphometric identification under stereo zoom microscope and dissecting microscope. According to the morphological identification of PCN cyst shape, cyst color and the vulval cone is observed. Morphometrics of PCN was recorded according to the measurements of main diagnostic characteristics such as body length, body width, neck length, distance from vulval basin to anus, number of cuticular ridges between vulval basin, and anus and Granek's ratio.

\section{Molecular characterization:}

DNA extraction and polymerase chain reaction: Genomic DNA was isolated from a pure population of 100 mature cysts by using Qiagen Puregene buccal cell kit following manufacturer procedure and quantify in nanodrop spectrophotometer and agarose gel. This resulted in DNA is amplified in PCR. For the amplification of DNA following primers were used i) forward primer SSU18A (AAAGATTAAGCCATGCATG) ii) reverse primer SSU26R (CATTCTTGGCAAATGCTTTCG). For master mix of 25ul reaction was set up consisting of $10 \mu \mathrm{l}$ of the DNA suspension was added to the PCR reaction mixture containing $0.2 \mathrm{mM} d N T P ' s, 0.2 \mu \mathrm{M}$ of each of the primer (reverse and forward) and $2.5 \mu \mathrm{l} 10 \times$ buffer $(10 \mathrm{mM}$ Tris- $\mathrm{HCl} \mathrm{pH} \mathrm{8.3,50} \mathrm{mM} \mathrm{KCl}, 1.5 \mathrm{mM} \mathrm{MgCl} 2), 1$ unit of Taq polymerase, and double distilled water to a final volume of $25 \mu$ l. The reaction conditions were:94 ${ }^{\circ} \mathrm{C}$ for 5 min; 35 cycles of $94{ }^{\circ} \mathrm{C}$ for 1 minute; $52^{\circ} \mathrm{C}$ for 1 minute $30 \mathrm{~s} ; 68^{\circ} \mathrm{C}$ for $2 \mathrm{~min} ; 68^{\circ} \mathrm{C}$ for $10 \mathrm{~min}$ Products $(5 \mu \mathrm{L})$ were visualized on agarose gels stained with ethidium bromide (Floyd et al. 2002). By the 
process of electrophoresis in Tris-Borate-EDTA (TBE) buffered 1.5\% agarose gels with ethidium bromide the PCR products were separated.

Data analysis: Nonparametric tests were performed to analyze the difference among the cyst populations. The differences of cyst population among the various locations within a single district were accessed by Kruskal Wallis Test and pairwise comparison between the locations was made by Dunn's Multiple Comparison Test. For comparison of two groups, Mann Whitney test was performed. Also, the complete data of districts (Mandi, Chamba, Kullu, Kangra) was made in the same manner. GraphPad PRISM 5.0 was used to perform the analysis. Data for Una, Hamirpur, and Solan was not taken for analysis as no cyst was found in the soil of these regions.

Sequencing and phylogenetic analysis: PCR products were purified according to manufacturer's protocol and Forward and reverse DNA sequencing reaction of PCR amplicon was carried out with forward primer and reverse primers using BDT v3.1 Cycle sequencing kit on ABI 3730xl Genetic Analyzer. The consensus sequence of $16 \mathrm{~S}$ rDNA gene was generated from forward and reverse sequence data using aligner software. The 16S rDNA gene sequence was used to carry out BLAST with the database of NCBI Genbank database. Based on the maximum identity score first ten sequences were selected and aligned using the multiple alignment software programs Clustal W. the phylogenetic tree was constructed using MEGA 7.

\section{Results And Discussion}

In Himachal Pradesh, the population ranged between 245cyst/250cc soil. In Himachal Pradesh, the population of the cyst ranged from minimum to maximum. In the district, Mandi samples were collected from four different areas i.e Basunti, Rewalsar, Phulladhar, and Dhanotu among these maximum populations of the cyst were collected from Basunti and Phulladhar samples. In Distt Chamba samples were collected again from four different areas i.e Ahla, Banikhet, Salooni, and Saru. Out of these four areas maximum cysts were collected from Ahla area. The third Distt was Kullu, samples were collected from four different areas; Bajaura, Bandrol, Anni, and Bhuntar. The maximum cyst population was collected from Bajaura area. From Distt Kangra samples were collected from eight different areas i.e Talpura, Kangra, Jiya, Skoh, Pariharkhar, Shahpur, Malan, and Bagoda out this Jiya area has the maximum number of the cyst. Samples were collected from Distt Una, Hamirpur, and Solan, particularly these sites i.e Akrot farm, Daulatpur, Rampur, TiraSujanpur, Nadaun, Kandaghat, and Darlaghat didn't recover cyst.

Table 2: Showing the morphometrics of Globoderarostochiensis cyst in $\mu \mathrm{m}$. ( \pm is mentioned as standard deviation).

In molecular characterization after sequencing, the resulted sequence were submitted to genebank NCBHI. Sequence ID MW577347 (HPPOCH) showing 99.05\% similarity with KJ636272.1 from the Netherlands. Sequence ID MZ508279 (HPPOKL) showing 95.58\% similarity with KJ636272.1 from the Netherlands. Sequence ID MZ508280 (HPPOMD) showing99.05\% similarity with KJ636272.1. Sequence I.D MZ518783 (HPPOPL) 98.58\% similarity with KJ636272.1 from the Netherlands. All the nucleotide sequences of Himachal Pradesh showing similarities with the Netherlands. 


\begin{tabular}{lll} 
Characters & Measurements in $\mu \mathrm{m}$ & $\begin{array}{l}\text { Table 3. Population density and frequency of } \\
\text { occurrence of PCN in various district of } \\
\text { Body length }\end{array}$ \\
\hline Body width & $613.08 \pm 23.96$ & Himachal Pradesh in potato growing fields. \\
\hline Neck length & $555.79 \pm 36.04$ & \\
\hline Distance from vulval basin to anus & $65.29 \pm 22.20$ &
\end{tabular}




\begin{tabular}{|c|c|c|c|c|c|c|c|c|c|c|}
\hline \multirow[t]{2}{*}{ Distt } & \multirow[t]{2}{*}{ Location } & \multicolumn{6}{|c|}{$\begin{array}{l}\text { Mean No. of cyst/ } 250 \mathrm{~g} \text { of soil from } \\
\text { different areas. }\end{array}$} & \multirow[t]{2}{*}{ Sum } & \multirow[t]{2}{*}{ P.D } & \multirow[t]{2}{*}{ Occurrence } \\
\hline & & 1 & & 2 & & 3 & & & & \\
\hline \multirow[t]{4}{*}{ Mandi } & Basunti & 50 & \pm 1.63 & 48 & \pm 2.16 & 45 & \pm 1.63 & 143 & 47.67 & 100 \\
\hline & Rewalsar & 10 & \pm 0.82 & 7 & \pm 1.70 & 12 & \pm 2.45 & 29 & 9.67 & 100 \\
\hline & Phulladhar & 55 & $\pm ` 3.74$ & 49 & \pm 5.31 & 48 & \pm 1.89 & 152 & 50.67 & 100 \\
\hline & Dhanotu & 5 & \pm 4.11 & 8 & \pm 4.19 & 5 & \pm 2.05 & 18 & 6 & 100 \\
\hline \multirow[t]{4}{*}{ Chamba } & Saru & 0 & \pm 0.00 & 2 & \pm 1.63 & 0 & \pm 0.00 & 2 & 0.67 & 33.33 \\
\hline & Ahla & 52 & \pm 2.16 & 50 & \pm 2.45 & 54 & \pm 2.49 & 156 & 52 & 100 \\
\hline & Banikhet & 20 & \pm 5.10 & 18 & \pm 3.30 & 18 & \pm 6.48 & 56 & 18.67 & 100 \\
\hline & Salooni & 5 & \pm 2.05 & 4 & \pm 1.70 & 5 & \pm 3.74 & 14 & 4.67 & 100 \\
\hline \multirow[t]{5}{*}{ Kullu } & Bajaura & 48 & \pm 5.25 & 45 & \pm 4.08 & 50 & \pm 10.96 & 143 & 47.67 & 100 \\
\hline & Bandrol & 4 & \pm 1.63 & 0 & \pm 0.00 & 0 & \pm 0.00 & 4 & 1.33 & 33.33 \\
\hline & Anni & 25 & \pm 5.10 & 16 & \pm 3.09 & 21 & \pm 4.50 & 62 & 20.67 & 100 \\
\hline & Bhuntar & 15 & \pm 2.45 & 14 & \pm 5.66 & 17 & \pm 2.16 & 46 & 15.33 & 100 \\
\hline & Talpura & 0 & \pm 0.00 & 0 & \pm 0.00 & 0 & \pm 0.00 & 0 & 0 & 0 \\
\hline \multirow[t]{7}{*}{ Kangra } & Kangra & 0 & \pm 0.00 & 0 & \pm 0.00 & 0 & \pm 0.00 & 0 & 0 & 0 \\
\hline & Jiya & 45 & \pm 2.49 & 48 & \pm 2.49 & 0 & \pm 0.00 & 93 & 31 & 66.66 \\
\hline & Skoh & 0 & \pm 0.00 & 0 & \pm 0.00 & 0 & \pm 0.00 & 0 & 0 & 0 \\
\hline & Parihar khar & 3 & \pm 1.41 & 1 & \pm 0.82 & 0 & \pm 0.00 & 4 & 1.33 & 66.66 \\
\hline & Shahpur & 0 & \pm 0.00 & 0 & \pm 0.00 & 0 & \pm 0.00 & 0 & 0 & 0 \\
\hline & Malan & 0 & \pm 0.00 & 0 & \pm 0.00 & 0 & \pm 0.00 & 0 & 0 & 0 \\
\hline & Bagoda & 0 & \pm 0.00 & 0 & \pm 0.00 & 0 & \pm 0.00 & 0 & 0 & 0 \\
\hline \multirow[t]{3}{*}{ Una } & Akrot farm & 0 & \pm 0.00 & 0 & \pm 0.00 & 0 & \pm 0.00 & 0 & 0 & 0 \\
\hline & Daulatpur & 0 & \pm 0.00 & 0 & \pm 0.00 & 0 & \pm 0.00 & 0 & 0 & 0 \\
\hline & Rampur & 0 & \pm 0.00 & 0 & \pm 0.00 & 0 & \pm 0.00 & 0 & 0 & 0 \\
\hline \multirow[t]{2}{*}{ Hamirpur } & Tirasujanpur & 0 & \pm 0.00 & 0 & \pm 0.00 & 0 & \pm 0.00 & 0 & 0 & 0 \\
\hline & Nadaun & 0 & \pm 0.00 & 0 & \pm 0.00 & 0 & \pm 0.00 & 0 & 0 & 0 \\
\hline \multirow[t]{2}{*}{ Solan } & Kandaghat & 0 & \pm 0.00 & 0 & \pm 0.00 & 0 & \pm 0.00 & 0 & 0 & 0 \\
\hline & Darlaghat & 0 & \pm 0.00 & 0 & \pm 0.00 & 0 & \pm 0.00 & 0 & 0 & 0 \\
\hline
\end{tabular}


P.D = cyst population density/total no. of samples, $\%$ occurence $=$ No. of positive samples $/$ total no. of samples x 100; \pm =standard deviation.

Result mentioned in the table.2 explains that the population density and \% occurrence of PCN greatly differs from examined locations. The population density and \% occurrence of PCN in Distt Mandi were highest and 100\%. Whereas Distt Kangra showed the lowest population density and \% occurrence. Soil samples collected from Distt Una, Hamirpur, and Solan were showed nil results from particular areas mentioned in the above table. Thus, data recorded during the survey conclude that Distt Mandi had the highest distribution of PCN and lowest in Distt Kangra. Such differences may occur due to location soil type, soil moisture, and irrigation system.

Statistical analysis of the cyst populations reveals some considerable results as given in Table 4 and 5 . Table 4 comprehends the summary of $P$ values for the test of differences between a different location within a district and all districts altogether. It can be seen that the cyst population was significantly different between the locations of district Mandi, Chamba, and Kullu. Also, the cyst populations between the districts (all locations altogether) are significantly different $(P<0.05)$. Figure $1-5$ depicts the graphical variation of cyst population between the groups.

Pair-wise comparisons between all the groups in concern have been done and its results have been comprehended in table 5. Most of the pairs are not found to be different in the cyst population except a few as mentioned. District Kangra is found to be different from all other districts in the cyst population.

Table 4: with P value for comparison of locations within the district/All districts

\begin{tabular}{|lllll|}
\hline Between locations of District & P Value & Significant? P $<$.05? & Test \\
\hline Mandi & 0.0261 & Yes & Kruskal-Wallis \\
Chamba & 0.0153 & Yes & Kruskal-Wallis \\
\hline Kullu & 0.0108 & Yes & Kruskal-Wallis \\
\hline Kangra & 0.0678 & No & Kruskal-Wallis \\
All districts & $<0.0001$ & Yes & Kruskal-Wallis \\
\hline
\end{tabular}

Table 5: with $\mathrm{P}$ value for pair wise comparison of locations/Districts 


\begin{tabular}{|c|c|}
\hline Locations in consideration & Significant? $P<0.05$ ? \\
\hline \multicolumn{2}{|l|}{ Mandi District } \\
\hline Basunti vs Rewalsar & No \\
\hline Basunti vs Phulladhar & No \\
\hline Basunti vs Dhanotu & No \\
\hline Rewalsar vs Phulladhar & No \\
\hline Rewalsar vs Dhanotu & No \\
\hline Phulladhar vs Dhanotu & Yes \\
\hline \multicolumn{2}{|l|}{ Chamba District } \\
\hline Saru vs Ahla & Yes \\
\hline Saru vs Banikhet & No \\
\hline Saru vs Salooni & No \\
\hline Ahla vs Banikhet & No \\
\hline Ahla vs Salooni & No \\
\hline Banikhet vs Salooni & No \\
\hline \multicolumn{2}{|l|}{ Kullu District } \\
\hline Bajaura vs Bandrol & No \\
\hline Bajaura vs Anni & No \\
\hline Bajaura vs Bhuntar & No \\
\hline Bajaura vs Talpura & Yes \\
\hline Bandrol vs Anni & No \\
\hline Bandrol vs Bhuntar & No \\
\hline Bandrol vs Talpura & No \\
\hline Anni vs Bhuntar & No \\
\hline Anni vs Talpura & No \\
\hline Bhuntar vs Talpura & No \\
\hline \multicolumn{2}{|l|}{ Kangra District } \\
\hline Kangra vs Jiya & No \\
\hline Kangra vs Skoh & No \\
\hline Kangra vs Parihar khar & No \\
\hline
\end{tabular}




\begin{tabular}{|ll|}
\hline Kangra vs Shahpur & No \\
\hline Kangra vs Malan & No \\
\hline Jiya vs Skoh & No \\
\hline Jiya vs Parihar khar & No \\
\hline Jiya vs Shahpur & No \\
\hline Jiya vs Malan & No \\
\hline Jiya vs Bagoda & No \\
\hline Skoh vs Parihar khar & No \\
\hline Skoh vs Shahpur & No \\
\hline Skoh vs Malan & No \\
\hline Skoh vs Bagoda & No \\
\hline Parihar khar vs Shahpur & No \\
\hline Parihar khar vs Malan & No \\
\hline Parihar khar vs Bagoda & No \\
\hline Shahpur vs Malan & No \\
\hline Shahpur vs Bagoda & No \\
\hline Malan vs Bagoda & No \\
\hline All Districts & No \\
\hline Mandi vs Chamba & No \\
\hline Mandi vs Kullu & No \\
\hline Mandi vs Kangra & Nes \\
\hline Chamba vs Kullu & No \\
\hline Chamba vs Kangra & Nullu vs Kangra \\
\hline
\end{tabular}

Globodera spp. was first reported in 1961 from Nilgiris district, Tamil Nadu, India. Ganguli et al. 2010 reported two species $G$. rostochiensis and G. pallida from the potato breeding farms in Kufri, Shimla District of Himachal Pradesh. District Shimla, Kullu, Mandi, Chamba and Kangra showed the prevalence of PCN. District Shimla, Kullu, Mandi and Kangra showed 100\% occurrence of PCN. Chandel et al. 2020 discussed the distribution of PCN in Himachal Pradesh, Jammu and Kashmir and Uttrakhand (northern hilly areas) India. Seenivasan et al. 2017 was conducted study for the distribution of PCN, G. rostochiensis and G. pallida in the potato fields of Kodaikanal hills, Tamil Nadu, India. Showed $36 \%$ of potato field is infested with 
the mixed population of PCN. Due to the increase in the infestation of PCN on potato fields especially in potato breeding farms as results government of India has restricted the supply of potato seeds from the infested areas of these states. There is urgent need of controlling the infestation of PCN on potato. This survey may help in figure out the prevalence and distribution of PCN in Himachal Pradesh and also for planning effective strategies against PCN. However, the use of organophosphorus compounds has been shown to control nematodes but may lead to toxicity and regular use of organophosphorus compounds subside the microbial community and reduces soil fertility (Sidhu et al. 2019). In a study it was observed that even the use of carbendazim can be toxic to soil microorganisms (Singh et al. 2016and that to nematode as well (Whitehead et al. 1985). Camacho et al. 2020 conducted the survey in Portugal during 2013-2019 and reported $28.6 \%$ population of $G$. rostochiensis and $49.4 \%$ population of $G$. pallida in collected soil samples from different areas. Which finally conclude that G. pallida detected greater than $G$. rostochiensis in the different potato fields of Portugal. In the way survey of potato field resulted mixed PCN population. But out of two $67 \%$ were G. pallida and $8 \%$ were G. rostochiensis (Minnis et al. 2002). Infestation of G. pallida is more as compare to G. rostochiensis in England fields. Przetakiewicz 2013 reported the G. rostochiensis pathotypes Ro5 in Poland. G. rostochiensis and G. pallida are also found in island of newfoundland and $G$. rostochiensis are found in the potato field of Saanich Peninsula of Vancouver Island, British Columbia, Canada (Sun et al. 2007). In Columbia G. pallida is the predominant species in potato cultivating fields and recorded from new areas also. All municipalities area samples were recorded positive (Vallejo et al. 2021). In Ukraine PCN identified on morphological and molecular basis. G. rostochiensis is more prevalent than G. pallida (Pylypenko et al. 2005). As per discussion the prevalence of Globodera spp is very high and there is a urgent need of planning effective and sustainable strategies against PCN.

\section{Declarations}

- Ethics approval and consent to participate- Not applicable.

- Consent for publication- the data collected in this survey by ourselves and it is original data. Consent is yes.

- Availability of data and materials- Random survey was done in the potato growing fields of Himachal Pradesh, India and all the material used in this survey is used according to the methodology discussed in the manuscript.

- Competing interests- Not applicable.

- Funding- Not applicable

- Authors' contributions

Ashvika Pathania-Survey, data collection and preparation of manuscript.

Dr Joydeep Dutta - Editing and finalization of manuscript.

Dr Shashank Garg - Statistical analysis. 
- Acknowledgements- The authors acknowledge the help for lab facilities provided by Lovely Professional University Phagwara Punjab, Sri Sai University Palampur Himachal Pradesh and Eurofins Pvt. Limited.

\section{References}

1. Bakr, R.A., Mahdy, M.E. and Mousa, E.M., 2011. A survey of root-knot and citrus nematodes in some new reclaimed lands in Egypt. Pakistan Journal of Nematology, 29(2), pp.165-170.

2. Camacho, M.J., de Andrade, E., Mota, M., Nobrega, F., Vicente, C., Rusinque, L. and Inácio, M.L., 2020. Potato cyst nematodes: Geographical distribution, phylogenetic relationships and integrated pest management outcomes in Portugal. Frontiers in Plant Science, 11.

3. Chandel, Y.S., Bhadu, S.S., Salalia, R., Thakur, S., Kumar, S., Somvanshi, V.S., Mukherjee, A. and Walia, R.K., 2020. Prevalence and spread of potato cyst nematodes, Globodera spp. in northern hilly areas of India. Current Science, 118(12), p.1946.

4. Cotton, J.A., Lilley, C.J., Jones, L.M., Kikuchi, T., Reid, A.J., Thorpe, P., Tsai, I.J., Beasley, H., Blok, V., Cock, P.J. and Eves-van den Akker, S., 2014. The genome and life-stage specific transcriptomes of Globodera pallida elucidate key aspects of plant parasitism by a cyst nematode. Genome biology, 15(3), pp.1-17.

5. Ebrahimi, N., Viaene, N., Demeulemeester, K. and Moens, M., 2014. Observations on the life cycle of potato cyst nematodes, Globoderarostochiensis and G. pallida, on early potato cultivars. Nematology, 16(8), pp.937-952.

6. Floyd, R., Abebe, E., Papert, A. and Blaxter, M., 2002. Molecular barcodes for soil nematode identification. Molecular ecology, 11(4), pp.839-850.

7. Ganguly, S., Singh, M. and Ganguly, A.K., 2010. Record of potato cyst nematode, Globodera rostochiensis and G. pallida in Shimla, Himachal Pradesh, India. Indian Journal of Nematology, 4O(1), pp.96-102.

8. Kaczmarek, A., MACKEnZiE, K., KEttIE, H. and BIOK, V.C., 2014. Influence of soil temperature on Globoderarostochiensis and Globodera pallida. Phytopathologia Mediterranea, pp.396-405.

9. Knoetze, R., Swart, A., Wentzel, R. and Tiedt, L.R., 2017. Description of Globodera sandveldensis n. sp. (Nematoda: Heteroderidae) from South Africa. Nematology, 19(7), pp.805-816.

10. Mimee, B., Dauphinais, N. and Belair, G., 2015. Life cycle of the golden cyst nematode, Globoderarostochiensis, in Quebec, Canada. Journal of nematology, 47(4), p.290.

11. Minnis, S.T., Haydock, P.P.J., Ibrahim, S.K., Grove, I.G., Evans, K. and Russell, M.D., 2002. Potato cyst nematodes in England and Wales-occurrence and distribution. Annals of Applied Biology, 140(2), pp.187-195.

12. Ohki, T., Narabu, T., Kushida, A., Onodera, K., Fujimoto, T., Itou, K. and Maoka, T., 2018. Molecular characterization of Globodera pallida found in Japan using ribosomal DNA and mitochondrial cytochrome b gene sequences. Journal of General Plant Pathology, 84(3), pp.230-236.

13. Phillips, M.S. and Trudgill, D.L., 1998. Variation of virulence, in terms of quantitative reproduction of Globodera pallida populations, from Europe and South America, in relation to resistance from Solanum vernei and S. tuberosum ssp. andigena CPC 2802. Nematologica, 44(4), pp.409-423. 
14. Ponce, J.F., 1977. Studies on the taxonomy and biology of potato cyst-nematodes, Globodera spp.

15. Przetakiewicz, A., 2013. The first report of Globodera rostochiensis pathotypes Ro5 occurrence in Poland. Plant disease, 97(8), pp.1125-1125.

16. Pylypenko, L.A., Uehara, T., Phillips, M.S., Sigareva, D.D. and Blok, V.C., 2005. Identification of Globodera rostochiensis and G. pallida in the Ukraine by PCR. European Journal of Plant Pathology, 111(1), pp.3946.

17. Seenivasan, N., 2017. Status of potato cyst nematodes Globoderaspp infection on potato at Kodaikanal hill of Tamil Nadu, India and yield loss estimation. J Ent and Zoo Studies, 5(5), pp.268-272.

18. Sidhu, G. K., Singh, S., Kumar, V., Dhanjal, D. S., Datta, S., \& Singh, J., 2019. Toxicity, monitoring and biodegradation of organophosphate pesticides: a review. Critical Reviews in Environmental Science and Technology, 49(13), pp1135-1187.

19. Singh, S., Singh, N., Kumar, V., Datta, S., Wani, A. B., Singh, D., ... \& Singh, J., 2016. Toxicity, monitoring and biodegradation of the fungicide carbendazim. Environmental Chemistry Letters, 14(3), pp317-329.

20. Skantar, A.M., Handoo, Z.A., Zasada, I.A., Ingham, R.E., Carta, L.K. and Chitwood, D.J., 2011. Morphological and molecular characterization of Globodera populations from Oregon and Idaho. Phytopathology, 101(4), pp.480-491.

21. Subbotin, S.A., Halford, P.D., Warry, A. and Perry, R.N., 2000. Variations in ribosomal DNA sequences and phylogeny of Globodera parasitising solanaceous plants. Nematology, 2(6), pp.591-604.

22. Subbotin, S.A., Vera, I.C.D.P., Mundo-Ocampo, M. and Baldwin, J.G., 2011. Identification, phylogeny and phylogeography of circumfenestrate cyst nematodes (Nematoda: Heteroderidae) as inferred from analysis of ITS-rDNA. Nematology, 13(7), pp.805-824.

23. Sun, F., Miller, S., Wood, S. and Côté, M.J., 2007. Occurrence of potato cyst nematode, Globodera rostochiensis, on potato in the Saint-Amable region, Quebec, Canada. Plant disease, 91(7), pp.908-908.

24. Vallejo, D., Rojas, D.A., Martinez, J.A., Marchant, S., Holguin, C.M. and Pérez, O.Y., 2021. Occurrence and molecular characterization of cyst nematode species (Globodera spp.) associated with potato crops in Colombia. Plos one, 16(7), p.e0241256.

25. Wainer, J. and Dinh, Q., 2021. Taxonomy, Morphological and Molecular Identification of the Potato Cyst Nematodes, Globodera pallida and G. rostochiensis. Plants, 10(1), p.184.

26. Whitehead, A. G., Bromilow, R. H., Fraser, J. E., \& Nichols, A. J. F., 1985. Control of potato cyst-nematode, Globodera rostochiensis, and root-knot nematode, Meloidogyne incognita, by organosphosphorus, carbamate, benzimidazole and other compounds. Annals of Applied Biology, 106(3), pp489-498.

\section{Figures}




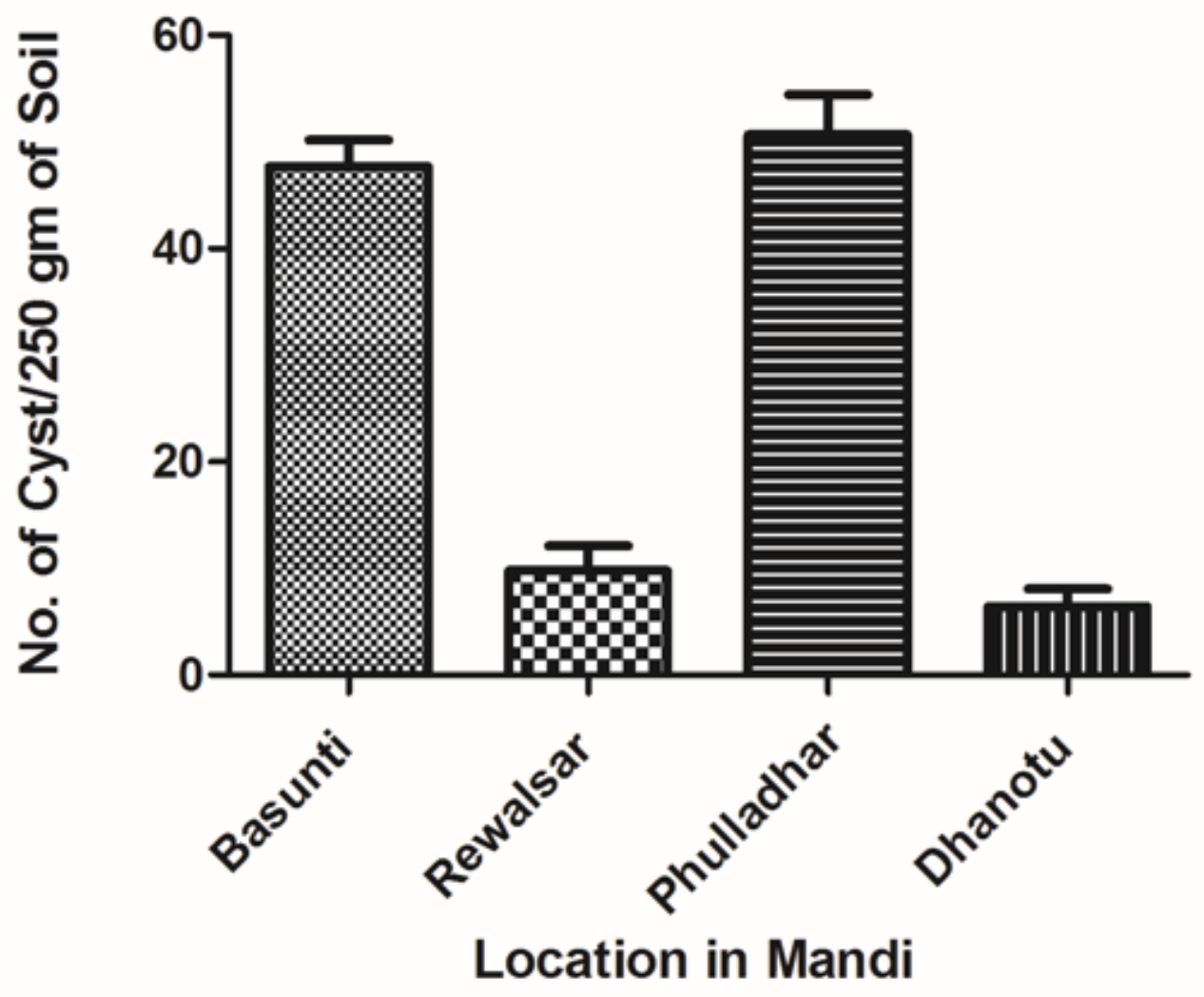

Figure 1

Histogram for cyst population in Mandi District 


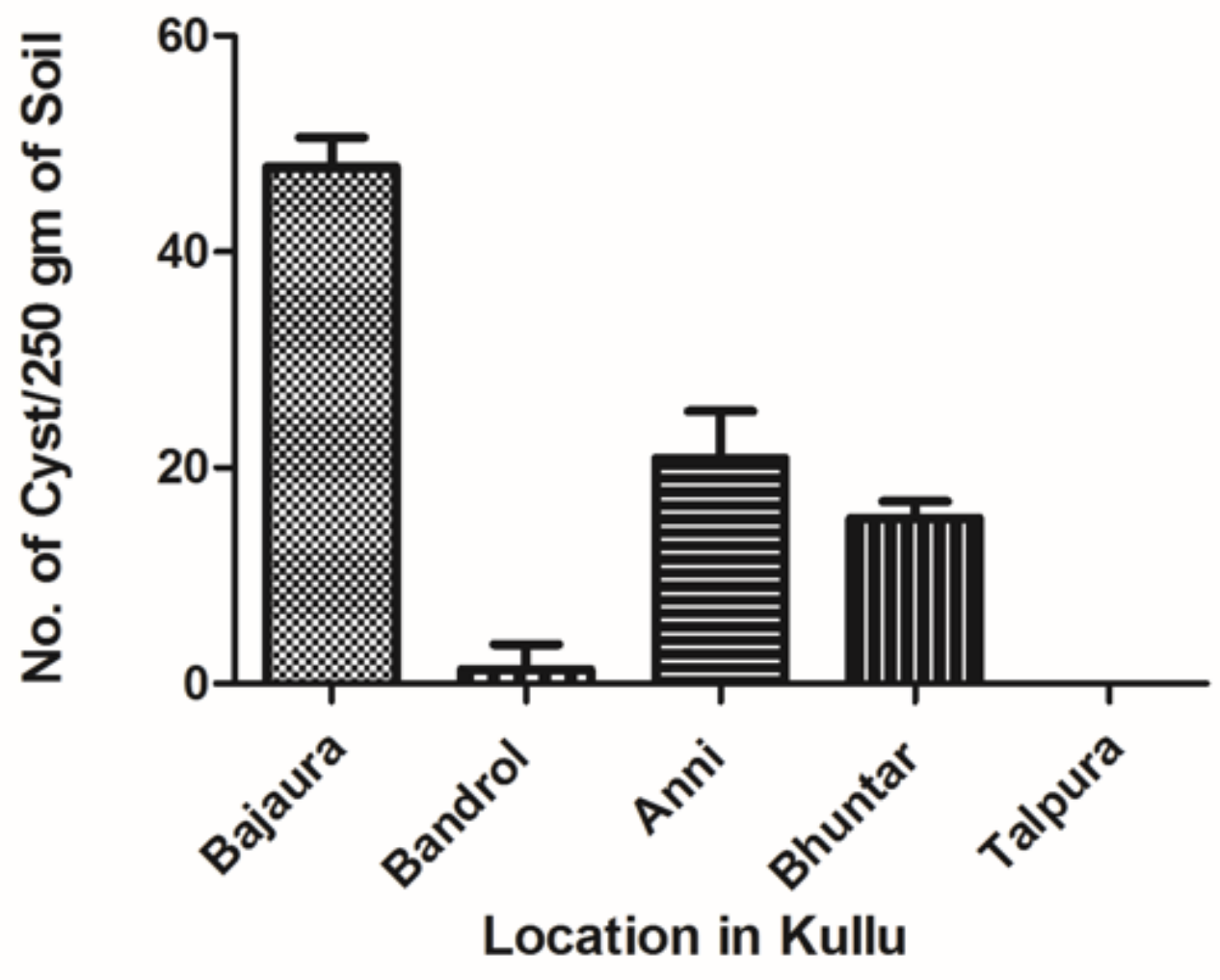

Figure 2

Histogram for cyst population in Kullu District

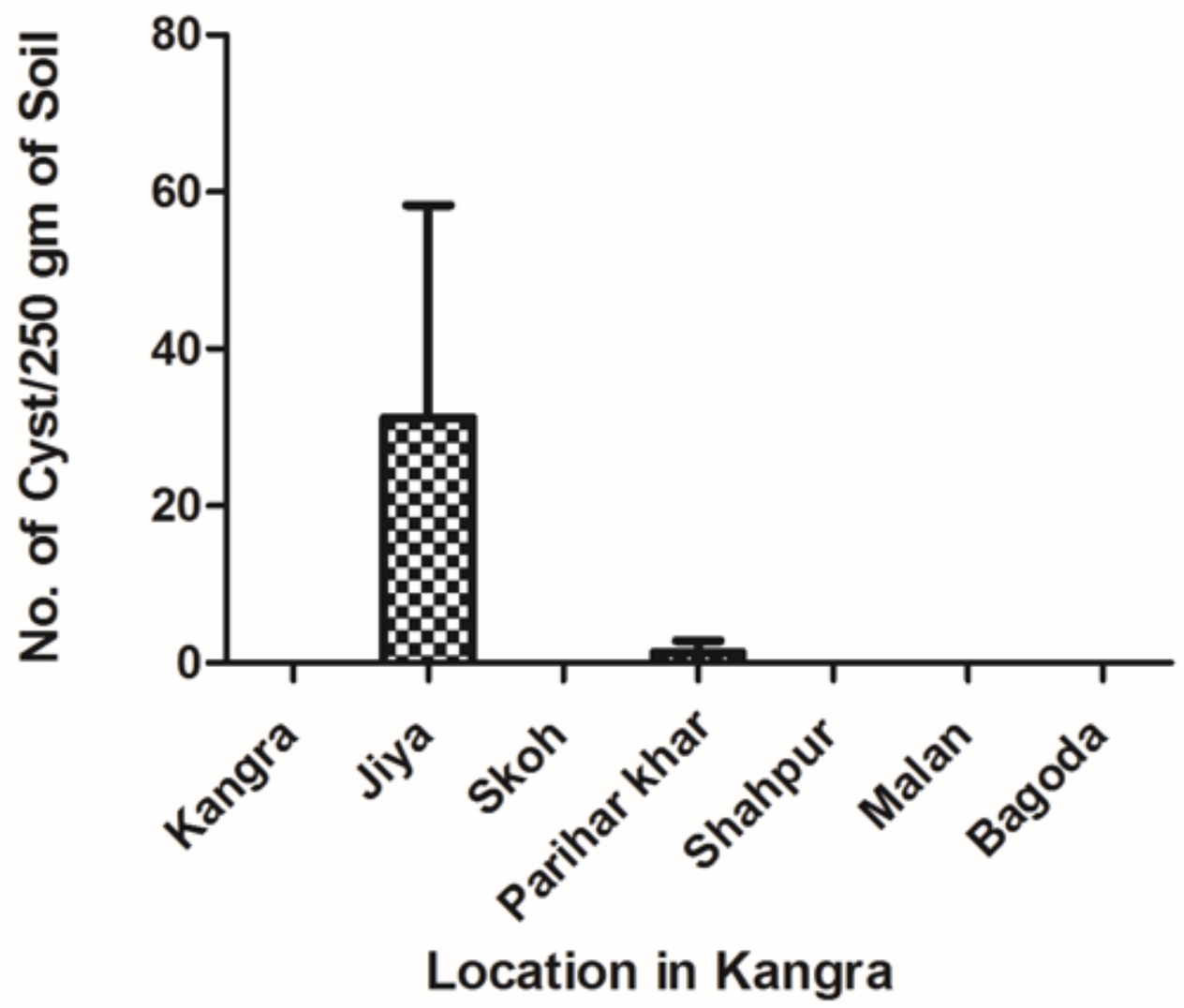


Figure 3

Histogram for cyst population in Kangra District

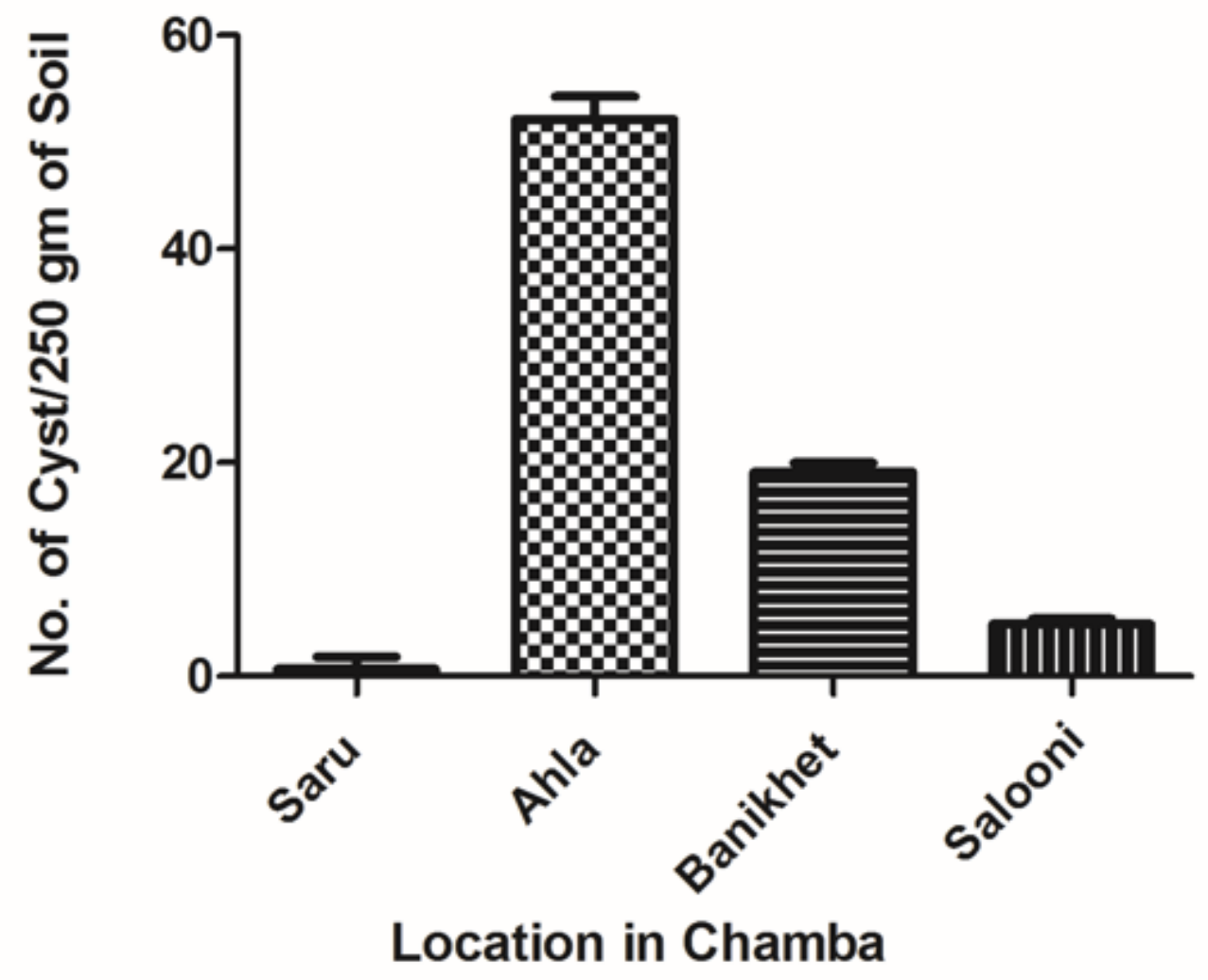

Figure 4

Histogram for cyst population in Chamba District 


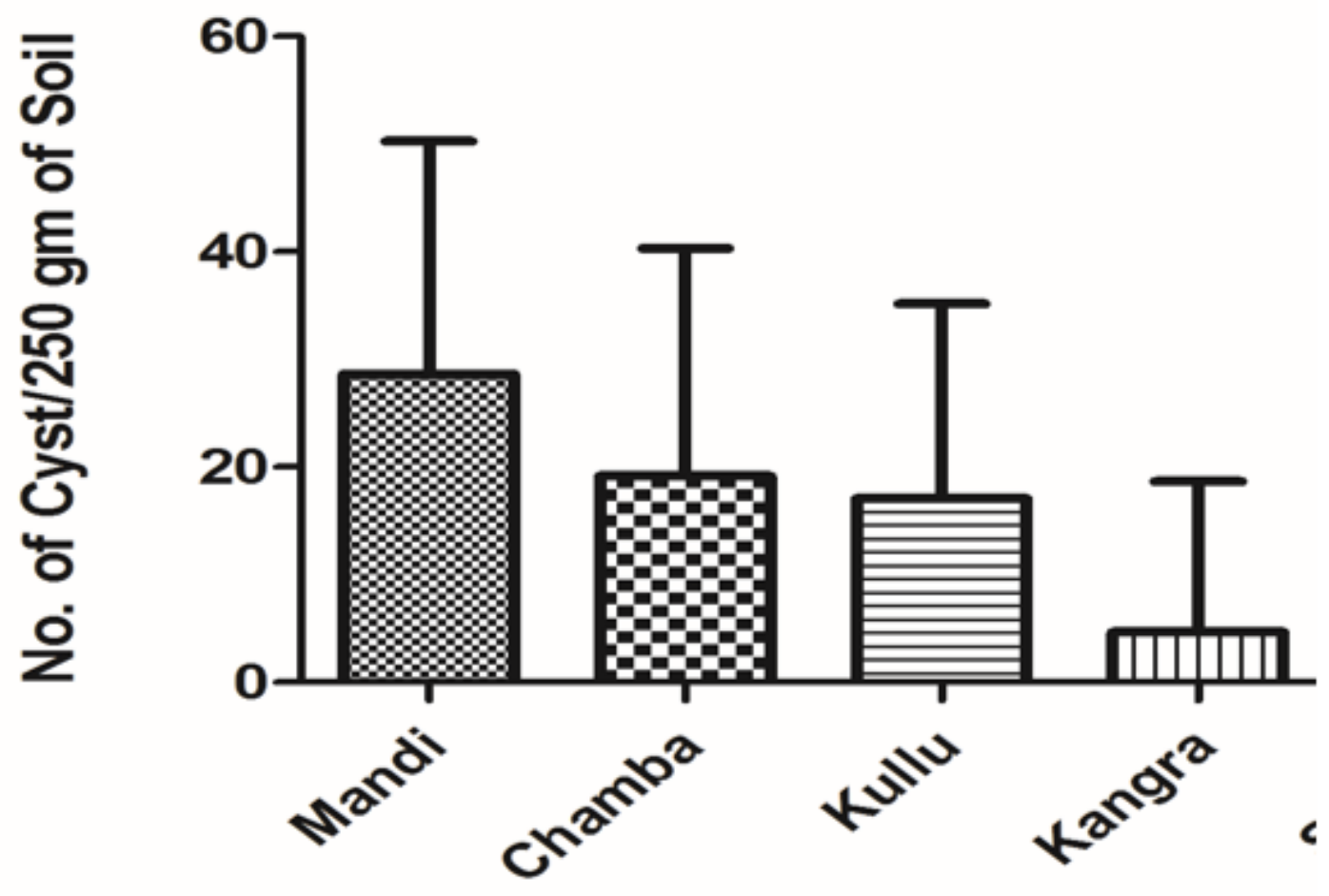

District

Figure 5

Histogram for cyst population in All districts together 